\title{
Application of gaseous ozone to inactivate Bacillus Cereus in processed rice.
}

\begin{abstract}
The effect of ozonation as a method to reduce Bacillus cereus count in processed rice was investigated. Hundred grams of processed rice was exposed to gaseous ozone in an inert glass condenser at $20 \pm 3 \mathrm{C}$ and $50 \%$ relative humidity. Ozone concentrations of $0.1,0.2,0.3$ and $0.4 \mathrm{ppm}$ up to $7 \mathrm{~h}$ were used. Enumerations of $\mathrm{B}$. cereus were done before ozonation treatment to establish the initial counts of B. cereus in processed rice. The experiments were done in an air-conditioned room and samples were then kept at ambient temperature pre- and post-ozonation to emulate normal conditions in rice storage facilities. Within $24 \mathrm{~h}$, the ozonated samples were then enumerated by surface spread plating technique. Significant trends were observed in comparison with the non-ozonated rice samples. Non-ozonated rice samples were found with an average of $5.50 \pm 0.28 \mathrm{log}$ count $(\mathrm{cfu} / \mathrm{g})$. Up to $1.63 \mathrm{log}$ reductions of $\mathrm{B}$. cereus counts were observed above $0.3 \mathrm{ppm}$ ozone concentration at the end of $420 \mathrm{~min}$ of treatment. B. cereus counts were shown to decrease to $3.62 \pm 0.38 \mathrm{log}$ count (cfu/g) at $0.4 \mathrm{ppm}$ ozone concentration for $420 \mathrm{~min}$ of ozone treatment.
\end{abstract}

Keyword: Bacillus Cereus. 